\title{
ObRAS DE ARTE SÃO ESSENCIALMENTE INSTITUCIONAIS? ${ }^{1,2}$
}

Rosi Leny Morokawa (UFRJ) $)^{3,4}$

rosimorokawa@gmail.com

Resumo: Este artigo examina os argumentos apresentados por Monroe Beardsley contra a tese de que a arte é essencialmente institucional. Beardsley mira sua crítica na versão mais bem elaborada de uma teoria institucional da arte, a teoria de George Dickie. Ele argumenta que Dickie usa o termo "instituição" de forma ambígua, como type e token, e que, afirmar a existência de um contexto institucional não é o mesmo que afirmar que as atividades que pressupõem este contexto são institucionais. Pretende-se mostrar que, embora Dickie reelabore sua teoria a fim de fortalecer sua tese inicial, ele não consegue responder de forma satisfatória ao "Argumento Beardsley-Anscombe". Além disso, este artigo apresenta e discute brevemente a última elaboração de Dickie, em que ele defende que a arte é uma espécie cultural.

Palavras-chave: Filosofia da arte; definição de arte; teoria institucional da arte; espécie cultural.

\section{INTRODUÇÃO}

Uma definição de arte, de forma geral, tenta especificar qual a natureza ou essência da arte. Tradicionalmente na filosofia, as teorias da arte buscam apresentar, por meio de

\footnotetext{
${ }^{1}$ Recebido em: 02-05-2018/ Aprovado em: 21-07-2018/ Publicado on-line em: 15-04-2021.

${ }^{2}$ Este artigo foi escrito, em parte, durante pesquisa financiada pela Fundação de Amparo à Pesquisa do Estado do Rio de Janeiro - FAPERJ.

${ }^{3}$ Doutoranda no Programa de Pós-graduação Lógica e Metafísica (PPGLM) da Universidade Federal do Rio de Janeiro (UFRJ), Rio de Janeiro, RJ, Brasil.

${ }^{4}$ ORCID: https://orcid.org/0000-0002-2115-4100.
} 
definições, propriedades comuns às obras de arte, que fazem algo ser arte e se distinguir daquilo que não é arte ${ }^{5}$. As principais teorias da arte formuladas na segunda metade do século XX tentam responder à posição que nega a existência de uma essência da arte que possa ser expressa em uma definição, em termos de condições necessárias e suficientes que devam ser satisfeitas para que algo seja arte ${ }^{6}$.

Uma famosa posição não definicional é a de Morris Weitz, em "The Role of Theory in Aesthetics" (1956)? Weitz nega que existam propriedades essenciais comuns às obras de arte e, até mesmo, que haja qualquer propriedade necessária que algo deva satisfazer para ser arte. Segundo sua proposta, as teorias tomam as propriedades acidentais ou contingentes como se elas fossem essenciais e, por isso, falham em apresentar uma propriedade (ou um conjunto de propriedades) que possa definir arte ${ }^{8}$.

Contra a posição de Weitz, Maurice Mandelbaum (1965) argumenta que é possível que existam propriedades comuns às obras de arte que não sejam nem intrínsecas e nem manifestas, mas que sejam propriedades relacionais. Sua objeção aponta o caminho das teorias que buscam definir arte a partir da relação entre obras arte e o contexto

\footnotetext{
${ }^{5}$ Para uma introdução ao problema da definição de arte, ver Morokawa (2020).

${ }^{6}$ Por condição necessária para algo ser arte, entende-se aquela condição que tudo que for arte deve satisfazer. Por condição suficiente para algo ser arte, entende-se aquela condição que tudo o que satisfaz essa condição seja arte, isto é, basta satisfazê-la para ser arte.

${ }^{7}$ Elaborada a partir de Investigações Filosóficas (1953) de Ludwig Wittgenstein. John Passmore (1951), Paul Ziff (1953) e William Kennick (1958), entre outros, também elaboraram propostas no mesmo sentido do que defendeu Weitz. Cf. Davies (1991). Para uma análise da tese de Weitz sobre a impossibilidade da definição de arte, objeções e perspectivas, ver Morokawa (2018).

${ }^{8}$ Por propriedades essenciais entende-se aquelas propriedades que algo não poderia deixar de ter e ainda assim existir ou ser o que é. Por propriedades acidentais, entende-se aquelas propriedades que algo poderia deixar de ter sem que com isso deixasse de existir ou ser o que é.
} 
cultural ou histórico delas. Uma destas teorias é a que ficou conhecida como "Teoria Institucional da Arte", proposta por George Dickie $(1974,1984)$.

Dickie propõe que a arte é institucional. Segundo Dickie (1974, p. 430), somente se "recuarmos um pouco e avaliarmos as obras no seu cenário institucional, seremos capazes de ver as propriedades essenciais que elas partilham". Para ele, as obras de arte partilham a propriedade de serem artefatos aos quais se atribuiu o estatuto de candidatos à apreciação. Esta atribuição confere um caráter institucional às obras de arte, porque é feita por representantes de uma certa instituição social que Dickie (1974, p. 431) chama de "mundo da arte".

Para Monroe Beardsley (1976), não há dúvidas de que os processos e produtos que em geral chamamos de "arte" estão muitas vezes relacionados com instituições sociais. Entretanto, ele considera que esta característica institucional da arte é algo meramente contingente. Em sua visão, a questão realmente importante é se a "arte é não apenas contingente, mas essencialmente institucional" (BEARDSLEY 1976, p. 125). Se a arte fosse essencialmente institucional, a propriedade de ser institucional seria necessária. Assim, seria impossível haver arte que não fosse institucional.

Beardsley considera que Dickie toma uma característica contingente como se fosse essencial. Segundo Beardsley, isso acontece porque Dickie usa um critério excessivamente fraco para caracterizar algo como institucional. Segundo este critério, algo é institucional porque sua classificação é instaurada por uma convenção. Para Beardsley (1976, p. 127), "quando falamos de uma atividade como institucio- 
nal, não é suficiente que a sua descrição seja uma descrição que foi instituída institucionalmente". Ou seja, do fato de uma ação ser descrita por uma descrição instituída por uma convenção não se pode concluir que a própria ação é institucional.

Para que a teoria institucional demonstre a tese de que a arte é essencialmente institucional, segundo Beardsley, ela deve mostrar que a existência de alguma instituição está incluída entre as condições de verdade de "A é uma obra de arte”. Se assim o fizer, então, obras de arte são objetos essencialmente institucionais. Veremos na resposta às críticas de Beardsley que Dickie tenta apresentar a existência de uma instituição entre as condições de verdade para se afirmar que algo é uma obra de arte.

As condições de verdade de uma sentença ou proposição são as condições que devem ser satisfeitas para que ela seja verdadeira. Quando Beardsley afirma que entre as condições de verdade de "A é uma obra de arte" deva estar incluída uma instituição, podemos supor que, para que a sentença seja verdadeira, a condição de existirem instituições deva ser satisfeita. Assim, a sentença só será verdadeira em uma situação em que existam instituições.

Dois argumentos contra a tese de Dickie são centralmente apresentados por Beardsley (1976): (1) o argumento de que Dickie confunde dois sentidos de instituição, como type e token, usando o termo "instituição" de forma ambígua; e (2) o que denomino "Argumento BeardsleyAnscombe", que defende que afirmar a existência de um contexto institucional não é o mesmo que afirmar que as atividades que pressupõem este contexto são institucionais.

Dickie (1984) reelabora sua teoria em resposta aos ar- 
gumentos de Beardsley. Neste artigo pretendo mostrar que Dickie não consegue responder de forma satisfatória ao Argumento Beardsley-Anscombe, que continua como uma forte objeção contra a tese da essência institucional da arte. Além disso, apresento outras críticas à reelaboração da teoria institucional da arte, assim como, mostro a crítica da circularidade na definição. E por fim, apresento e analiso brevemente a última elaboração de Dickie (2000, 2001, 2004) sobre a arte como uma espécie cultural, na qual ele propõe uma versão reduzida da teoria das espécies naturais.

\section{A Teoria Institucional da Arte, De George DICKIE}

Dickie elabora sua teoria institucional da arte influenciado por Arthur Danto9. Segundo Dickie, Danto (1964) mostra com o problema dos pares indiscerníveis - em que um objeto é uma obra de arte enquanto outro objeto com as mesmas características perceptuais não é - a necessidade de que uma definição de arte seja elaborada a partir de propriedades não intrínsecas às obras de arte. A partir disto, Dickie afirma que a condição de ser obra de arte é fruto de uma atribuição institucional que faz com que apenas um dos objetos indiscerníveis perceptualmente seja arte.

A expressão "mundo da arte" de Danto (1964) é interpretada por Dickie (1974, p. 429) referindo-se a uma "insti-

\footnotetext{
${ }^{9}$ Dickie aponta que Danto não elaborou uma teoria institucional da arte, mas considera que as observações sobre a atribuição do estatuto de arte, apresentadas em "Artworks and Real Things" (1973), assemelham-se a uma teoria institucional. Assim, para Dickie, a teoria institucional da arte é uma versão possível de uma teoria da atribuição de estatuto apresentada inicialmente por Danto.
} 
tuição social alargada na qual as obras de arte têm o seu lugar próprio". Ele usa a expressão "instituição social” para designar uma "prática estabelecida [established practice]", algo não tão formal como uma "sociedade ou uma corporação estabelecida” (DICKIE 1974, p. 430).

O mundo da arte é apresentado por Dickie (1974, p. 430) como "um feixe de sistemas [...], cada um dos quais proporciona um contexto institucional para a atribuição do estatuto a objetos pertencentes ao seu domínio”. Quando avaliamos cada um desses sistemas somos capazes de reconhecer a propriedade essencial que eles partilham, a saber, a ação de atribuição do estatuto de arte. Esta ação para Dickie sempre esteve presente nas artes, mas os espectadores, críticos e filósofos voltavam suas atenções às propriedades do objeto adquiridas pela ação e não para a ação em si.

A definição institucional da arte é elaborada em termos de duas condições necessárias e conjuntamente suficientes para que algo seja arte, a artefatualidade e a atribuição do estatuto de arte:

Uma obra de arte no sentido classificatório é (1) um artefato (2) com um conjunto de aspectos que fez com que lhe fosse atribuído o estatuto de candidato à apreciação por parte de alguma pessoa ou pessoas agindo em nome de uma certa instituição social (o mundo da arte). (DICKIE 1974, p. 431, tradução minha) ${ }^{10}$.

Dickie deixa claro que a definição é em "sentido classificatório" para se diferenciar de definições valorativas da ar-

\footnotetext{
${ }^{10}$ A definição apresentada em 1974 é a versão mais conhecida e bem elaborada de sua teoria. Embora Dickie tenha apresentado anteriormente versões prévias a esta, neste artigo, me refiro à versão de 1974 como a primeira elaboração e à versão de 1984, como a reelaboração da teoria institucional da arte.
} 
te. Assim, ele considera que algo pode ser arte sem ser boa arte. A condição (1), a artefatualidade, define arte como um produto da atividade humana. Esta condição pode ser adquirida por objetos manufaturados, como no caso de readymades $^{11}$, ou objetos naturais quando deslocados de seus locais originais $^{12}$. A condição (2), a atribuição do estatuto de arte, é apresentada em quatro noções interligadas: agir em nome de uma instituição; atribuir um estatuto; ser um candidato e a apreciação.

\section{BeARdSley E A CRÍTICA À TEORIA INSTITUCIONAL DA ARTE}

A teoria institucional proposta por Dickie é a versão mais conhecida de uma teoria institucional da arte. Beardsley considera que o argumento de Dickie é complexo e bem elaborado, mas parece insuficiente como uma definição de arte. Apesar de Beardsley ter discutido vários aspectos da teoria institucional da arte, neste artigo veremos centralmente dois argumentos. $\mathrm{O}$ primeiro argumento é o da ambiguidade do uso do termo "instituição", que é reconhecido por Dickie na reelaboração da sua teoria. $\mathrm{O}$ segundo é o Argumento Beardsley-Anscombe que, como propõe este artigo, não consegue ser respondido por Dickie de forma satisfatória. De modo que, este argumento continua

\footnotetext{
11 "Ready-made" foi um termo utilizado pelo artista Marcel Duchamp (1887-1968) para se referir às suas obras compostas por objetos manufaturados que escolhia, segundo ele, sem critérios estéticos. A Fonte, um urinol invertido com a inscrição "R. Mutt", enviado ao Salão dos Independentes de Nova Iorque em 1917, é um dos seus ready-mades mais conhecidos.

${ }^{12} \mathrm{Na}$ reelaboração da teoria institucional, Dickie (1984, p. 117) considera que a artefatualidade não pode ser conferida a um objeto, mas que ela é fruto de um trabalho mínimo do artista, mesmo nos casos de ready-mades.
} 
incidindo sobre a reelaboração da teoria institucional.

\subsection{A AMBIGUIDADE NO USO DE “INSTITUIÇÃO”}

Beardsley argumenta contra a teoria institucional da arte afirmando que Dickie faz uma confusão entre dois sentidos de "instituição". Beardsley (1976, p. 126) afirma que há uma ambiguidade no termo "instituição". Ele pode ser usado para designar uma instituição type e para designar uma instituição token. Segundo esta distinção, uma instituição token "é uma entidade coletiva que é individualizada por conjuntos de práticas persistentes [...] e possui certa soberania, isto é, a autoridade para manter ou alterar as práticas" (BEARDSLEY 1976, p. 126) ${ }^{13}$. Por instituições type, Beardsley entende o conjunto de práticas comuns a um grupo de pessoas, como a do casamento, divórcio, ritos de iniciação. As práticas comuns tornam-se práticas institucionalizadas na medida em que são associadas a certas instituições tokens, segundo Beardsley (1976, p. 126). Assim, para Beardsley (1976, p.135), uma prática estabelecida não é uma instituição token, como uma fábrica ou um teatro. Uma prática estabelecida pode ser uma prática social como esculpir, escrever poemas, compor música e assim por diante. Nem todas as práticas sociais são institucionalizadas. Sua institucionalização depende da relação das práticas sociais com as instituições instanciadas, ou seja, instituições tokens.

Dickie (1974, p. 430) afirma que ao classificar o mundo

${ }^{13}$ Como por exemplo a realização de reuniões regulares em que certas cerimônias são realizadas. 
da arte como uma instituição, ele busca designar "uma prática estabelecida, e não uma sociedade ou corporação estabelecida”. Porém, mesmo que Dickie considere instituição como uma prática estabelecida, faz uso da noção de autoridade de conferir o estatuto, que parece estar ligada a uma sociedade ou corporação no sentido de instituição do qual quer se afastar.

Assim, para Beardsley (1976, p. 134), há um problema com o conceito de "agir em nome de" na definição institucional. Podemos imaginar que alguém agindo em nome de uma instituição token poderia conceder o estatuto a algo ou alguém. Como, por exemplo, o Reitor de uma universidade concede o título de Doutor a um professor (exemplo utilizado por Dickie e Beardsley). Mas o mundo da arte não é feito de instituições tokens. Uma vez que Dickie faz uso do sentido mais amplo de "instituição" para designar práticas gerais, Beardsley questiona se faz sentido falar de agir em nome de uma prática. A autoridade de atribuição de um estatuto pode ser centralizada em uma instituição token. No entanto, para práticas estabelecidas, como Dickie concebe o mundo da arte, "parece faltar a fonte da autoridade necessária” (BEARDSLEY 1976, p. 134) para conferir a qualidade de candidatura à apreciação.

\subsection{O ARGUMENTO BEARDSLEY-ANSCOMBE}

O Argumento Beardsley-Anscombe tem por base a distinção entre ações que são institucionais e as que não são. A instauração de uma convenção não faz de uma ação algo institucional. Por exemplo, acenar um "até logo" com a 
mão tem em nossa cultura uma base convencional, mas não é parte de uma instituição, afirma Beardsley (1976, p. 127) ${ }^{14}$. Para Beardsley, alguns fatos podem ser instituídos por uma convenção. Podemos entender que esses fatos pressupõem um contexto institucional. No entanto, pressupor um contexto institucional não é o mesmo que afirmar que o fato seja uma descrição deste contexto institucional.

A defesa de Beardsley, de que há uma distinção entre fatos que são ou não institucionais e que isto se aplica à atividade artística, se deve a Elizabeth Anscombe em "On brute facts" (1958). Neste curto artigo ela discute brevemente a relação entre fatos e o contexto institucional por trás deles. Segundo Anscombe, alguns fatos pressupõem um contexto institucional, que em algum momento se convencionou certas práticas. No entanto, não devemos dizer que são fatos mantidos no contexto de instituições, pois suas descrições não descrevem algo sobre este contexto. Em circunstâncias normais, estas descrições são sobre fatos brutos em relação a outros fatos (ANSCOMBE 1958, p. 70). Segundo Anscombe,

A afirmação de que eu devo ao merceeiro não contém uma descrição de nossas instituições, não mais do que a afirmação de que eu dei a alguém um schilling contém uma descrição da instituição do dinheiro e da moeda do país. Por outro lado, requer estas ou muitas semelhantes instituições como pano de fundo a fim de que seja o tipo de

\footnotetext{
${ }^{14}$ Beardsley (1976, p. 127) apresenta outro exemplo, o de um legislador que aprovasse uma lei em que se considere a morte como a cessação da atividade cerebral. Nesse caso, embora a definição de morte como cessação da atividade cerebral seja dada por uma instituição, criando-se uma norma para o uso do termo "morte", isto não faz da morte em si algo institucional. A morte existe antes de uma definição normativa do conceito de morte ou de relações com instituições jurídicas.
} 
declaração que é. (ANSCOMBE 1958, p. 69, tradução minha).

Considerando o seguinte caso: (x) eu pedi batatas; (y) o merceeiro me entregou as batatas; $(z)$ o merceeiro enviou a conta. Para Anscombe (1958, p. 70), a descrição A “ Eu devo ao merceeiro" pressupõe um contexto institucional, em que em algum momento se convencionou certas práticas como a de compra e venda. No entanto, "dever ao merceeiro" não descreve algo sobre este contexto.

Anscombe (1958, p. 72) afirma que a existência da descrição A na linguagem em que ocorre pressupõe um contexto a que chamamos de “a instituição por trás de A". Esse contexto pode ou não ser pressuposto para as descrições xyz. Por exemplo, a instituição de compra e venda é pressuposta para a descrição $z$, como também é para $A$, mas não é para as descrições y e x. Em nenhuma destas descrições está presente, nem mesmo implicitamente, uma descrição do contexto das instituições. Por conseguinte, "A" não é uma descrição de "a instituição por trás de A" mesmo que a pressuponha.

Partindo de Anscombe, Beardsley (1976, p. 127) apresenta o exemplo de Jones e Smith. O primeiro deposita seu salário em um banco, o segundo, guarda suas joias atrás de um tijolo na chaminé de sua casa. A ação de Jones é claramente institucional porque pressupõe a existência de uma instituição, o banco, com a qual se relaciona diretamente para executar a ação de depositar o dinheiro. Por outro lado, a ação de Smith não é institucional, pois para desempenhá-la não há necessidade de qualquer relação com instituições. Mesmo que as duas ações sejam realizadas por um motivo similar, as duas ações se diferenciam quanto a 
serem institucionais ou não.

A questão relevante para Beardsley (1976, p. 127-128) é a forma como a distinção entre fatos que são ou não institucionais se aplica à atividade artística, e mais especificamente à criação da obra de arte. A imagem que podemos ter do artista romântico "retirado em sua torre de marfim" se assemelha mais a Smith do que a Jones. Segundo Beardsley,

É claro que não se pode negar que ao artista romântico pode ser fornecida energia elétrica por uma instituição, que o seu papel ou tela têm de ser fabricados, que seus próprios pensamentos serão [...] em certo ponto "moldados" pela linguagem adquirida e aculturação prévia. Mas nada disso importa ao lado do ponto em questão, segundo o qual (nesta versão) ele pode fazer uma obra de arte e validálo como tal, pela sua própria força originária livre. (BEARDSLEY 1976, p. 127-128, tradução minha).

Beardsley não defende a concepção do artista romântico ou isolado como modelo de se produzir arte, mas nota que se é possível que exista ou existiu este tipo de artista, ele se constitui em uma antítese à teoria institucional da arte. A concepção do artista romântico defende que o artista pode fazer uma obra de arte sem que a ação de criação e o produto dela sejam institucionais (BEARDSLEY 1976, p. 127). Até que o artista resolva expor ou vender a obra em contato direto com instituições, a arte não tem um caráter institucional, pois ela não se relaciona com instituições. Assim, obras de arte são criadas, existem, antes mesmo de sua relação com as instituições da arte. Um exemplo, ao qual podemos nos remeter, são as obras produzidas por Arthur Bispo do Rosário (1909-1989), cuja produção foi feita re- 
clusa em um hospital psiquiátrico ${ }^{15}$. Bispo do Rosário produziu uma série de objetos com preocupações estéticas, que para ele tinham fins religiosos. Ele é atualmente considerado um expoente da arte contemporânea brasileira e suas obras fazem parte do acervo de vários museus.

\section{A REELABORAÇÃO DE DiCKIE EM RESPOSTA A BEARDSLEY}

A reelaboração da teoria institucional da arte em The Art Circle (1984) é centrada no que Dickie (1984, p. 156) chama de "enquadramento [framework] essencial da arte", que envolve o artista, o público e o mundo da arte. Ele apresenta a teoria institucional da arte em cinco definições articuladas entre si,

A) Um artista é uma pessoa que participa, com conhecimento de causa, na produção de uma obra de arte;

B) Uma obra de arte é um artefato de uma espécie criada para ser apresentada a um público do mundo da arte;

C) Um público é um conjunto de pessoas que estão preparadas, em certo grau, para compreender um objeto que lhes é apresentado;

D) $\mathrm{O}$ mundo da arte é a totalidade dos sistemas do mundo da arte;

E) Um sistema do mundo da arte é um enquadramento para a apresentação, por um artista, de uma obra de arte a um público do mundo da arte. (DICKIE 1984, p. 156-159)

Dickie aceita parcialmente a crítica de Beardsley à sua teoria, o que o leva à elaboração das cinco definições. Por um lado, Dickie se propõe a corrigir sua concepção de natureza institucional da arte. Por outro, ele se concentra na

\footnotetext{
${ }^{15}$ Bispo do Rosário viveu por mais de cinquenta anos recluso na Colônia Juliano Moreira, uma instituição psiquiátrica na cidade do Rio de Janeiro, que hoje abriga o Museu Bispo do Rosário.
} 
concepção de artista romântico de Beardsley para "usá-la como contraponto no desenvolvimento de uma explicação da natureza institucional da arte" (DICKIE 1984, p. 122). Veremos a seguir esses dois aspectos da resposta de Dickie à crítica de Beardsley, na elaboração da nova versão da teoria institucional da arte.

\subsection{ACEITAÇÃO DO ARGUMENTO SOBRE A AMBIGUIDADE DO TERMO “INSTITUIÇÃO”}

Dickie (1984, p. 114) reconhece que Beardsley está correto em sua crítica e que a primeira formulação da teoria institucional não é coerente. $O$ mundo da arte é apresentado na primeira definição institucional como uma prática social e não como uma instituição instanciada. O que não condiz com as expressões "conferir", "estatuto" e "agir em nome de", excessivamente formais e mais apropriadas ao âmbito de instituições tokens, como Beardsley as concebe. $\mathrm{O}$ uso destas expressões, segundo Dickie, o levaram a oferecer descrições inexatas do mundo da arte. No entanto, a admissão de que a primeira elaboração da teoria institucional é incorreta não implica que toda formulação da teoria institucional seja incorreta, alega Dickie.

Por conseguinte, na reelaboração da teoria institucional, Dickie abandona a condição de atribuição de estatuto de candidato à apreciação de sua definição de $\operatorname{arte}^{16}$. Este abandono se deve à aceitação da crítica de Beardsley de que

\footnotetext{
${ }^{16}$ Quando Dickie (1984) retira de sua definição a "atribuição de candidato à apreciação" feita pelos representantes do mundo da arte, ele acaba por apresentar algo como a definição de Diffey (1969), que nada é arte a não ser que passe por uma "exibição pública".
} 
o mundo da arte não seria uma instituição do gênero que confere estatutos (DICKIE 1984, p. 114). Grosso modo, o que agora ele designa como teoria institucional da arte é "a visão segundo a qual uma obra de arte é arte por causa da posição que ocupa dentro de uma prática cultural, ou seja, como é evidente, dentro de uma instituição type, na terminologia de Beardsley" (DICKIE 1984, p. 124).

\subsection{A DEFESA DO ENQUADRAMENTO ESSENCIAL DA ARTE}

Dickie (1984, p. 111) afirma que por abordagem institucional refere-se "à ideia segundo a qual as obras de arte são o resultado da posição que ocupam dentro de um enquadramento ou de um contexto institucional”. Essa ideia é defendida a partir de Danto (1964). O que há em comum entre a perspectiva de Danto e a teoria institucional, de acordo com Dickie (1984, p. 115), "é a tese segundo a qual obras de arte estão imersas num enquadramento ou contexto essencial e de considerável "espessura".

Ele tenta demostrar que o enquadramento é essencial para a criação das obras de arte. Ele acredita que assim possa mostrar que existe uma natureza institucional da arte. Dickie (1984, p. 122) afirma que "sua teoria sustenta que a institucionalidade é uma condição tanto necessária como suficiente" para a existência de obras de arte. Segundo Dickie, Beardsley não teria mostrado que a institucionalidade não é uma condição suficiente para definir arte com a concepção do artista romântico. E que, ainda que Beardsley tivesse demonstrado que não há uma condição suficiente, ela ainda poderia ser uma condição necessária.

Para defender que a concepção do artista romântico 
não contraria eficazmente a teoria institucional da arte, Dickie retoma a seguinte passagem de Beardsley (1976, p. 127-128): "que seus próprios [do artista] pensamentos serão [...] em certo ponto 'moldados' pela linguagem adquirida e aculturação prévia”.

Se os pensamentos do artista são culturalmente moldados, os seus pensamentos sobre a própria arte também o são. Assim, Dickie acredita que há bons motivos para pensar que a arte que o artista cria é essencialmente institucional. Por "pensamentos relevantes" sobre a arte, Dickie (1984, p. 125-126) entende "os pensamentos sobre objetos que são reconhecidos como arte pela pessoa que os está a ter, são pensamentos sobre a atividade de produção de arte e outros semelhantes". Em outras palavras, "os pensamentos relevantes são os que envolvem certo grau de entendimento do conceito de arte" (DICKIE 1984, p. 125). Para Dickie, se os artistas criam obras de arte em parte com estes pensamentos sobre arte, isto é, possuem um entendimento sobre o conceito de arte, está aberta a possibilidade de que uma instituição da arte possa ser uma condição para que estas obras sejam arte.

Os pensamentos sobre arte envolvem algo que podemos chamar de "instituição da arte" porque os "artistas empregam tais pensamentos, consciente ou inconscientemente, como um enquadramento dentro do qual trabalham" (DICKIE 1984, p. 126). O enquadramento, segundo Dickie (1984, p.127), "é habitualmente adquirido através da experiência de obras de arte, do treino das técnicas artísticas, do conhecimento de fundo sobre a arte". Por mais que o artista se retire do contato com as instituições sociais, ele não poderia retirar-se da instituição da arte, porque ela é trans- 
portada com o artista tal qual Robinson Crusoé transporta consigo para a ilha sua cultura inglesa (DICKIE 1984, p. 121).

Para Dickie (1984, p. 126-127), Beardsley não deixa claro que a arte pode ser criada fora deste enquadramento, mesmo que sua intenção seja essa, visto que, afirma que os próprios pensamentos são moldados pela sua linguagem adquirida e pela aculturação anterior. Somente se entendermos o "poder originário livre" do artista como uma capacidade de criar obras de arte independentemente do enquadramento dentro do qual o artista trabalha, segundo Dickie, a noção de artista romântico se tornaria eficaz contra a tese institucional. Algo que ele considera implausível.

Seria possível imaginar que um membro de uma tribo primitiva, desprovido de qualquer concepção sobre arte, possa empregar um tipo de enquadramento originário, segundo Dickie. Mas o que este experimento de pensamento demonstra é que "é logicamente possível que a arte, juntamente com seu enquadramento, tenha uma ocorrência romântica" (DICKIE 1984, p. 129), ou seja, que a instituição da arte surja no momento da criação de uma obra de arte. Neste caso, para Dickie, a arte não seria criada independentemente de um enquadramento, mas o enquadramento seria criado com a criação de obras de arte.

A conclusão de Dickie (1984, p. 143), ao descrever o enquadramento essencial da arte, é de que há duas condições necessárias para que algo seja arte: (1) ser um artefato e (2) ser de um tipo criado para ser apresentado a um público do mundo da arte. Estas duas condições implicam em regras que são conjuntamente suficientes para se criar uma obra de arte. Os papéis, desempenhados pelo artista e pelo 
público, são desenvolvidos historicamente e aprendidos por convenções, dentro de um enquadramento que se mantém ao longo do tempo (DICKIE 1984, p. 141-150).

\section{A INSUFICIÊNCIA DA RESPOSTA DE DICKIE E CRÍTICAS À REELABORAÇÃO DA TEORIA INSTITUCIONAL DA ARTE}

Para Dickie (1984, p. 125-126), todos os artistas, ao criarem obras de arte usam certos conceitos sobre arte, que são pensamentos moldados pela linguagem e aculturação. Esses pensamentos sobre arte, segundo Dickie, constituem um enquadramento no interior do qual o artista produz obras de arte. Por sua vez, o enquadramento possui uma base convencional, que se mantém em todos os sistemas do mundo da arte (DICKIE 1984, 150). E, um artista não pode criar uma obra de arte fora desse enquadramento, o que o leva a concluir que a arte é institucional.

Todavia, do fato de todos os artistas criarem em um enquadramento e os conceitos que envolvem a arte terem uma base convencional, não se pode concluir que a criação de obras arte seja institucional. Tampouco, que a arte seja institucional.

Beardsley argumenta que a criação de obras de arte, ainda que pressuponha um contexto institucional, em si mesma não é institucional. Ser ou não institucional depende da relação de certas práticas com instituições instanciadas, mesmo no sentido de uma instituição type. Muitas pessoas têm certas práticas, aprendidas culturalmente, porém isto não faz com que estas práticas sejam institucionais. Por exemplo, o fato de todos escovarem os dentes faz disto 
uma prática geral, mas não faz de escovar os dentes algo institucional. "A diferença entre escovar os dentes e o enterro dos mortos é que a última prática está associada a várias outras práticas religiosas e civis, que lhe dão um caráter institucional" (BEARDSLEY 1976, p. 130).

Do fato de uma prática ser adquirida convencionalmente, como a prática de pintar, não podemos concluir que o que se cria com ela, isto é, uma pintura ou uma obra de arte, seja institucional. Parece haver uma confusão entre a linguagem e o que fazemos com ela e os objetos do mundo. Algumas convenções iniciam e mantém uma prática artística. No entanto, isso não é suficiente para caracterizar o fenômeno da arte, ou seja, a arte ela mesma, como institucional. Desse modo, a reelaboração da teoria institucional da arte parece não escapar ao Argumento BeardsleyAnscombe, que se mantém como uma objeção à posição subscrita por Dickie. Dickie continua tratando a instauração de uma convenção, que deu início a uma prática - a que ele chama de "instituição" - como o critério para afirmar que algo (uma obra de arte) realizado dentro desta prática é institucional. Um critério fraco.

Além disso, é plausível a defesa de que a arte pode ser criada sem o conceito de arte, essa é uma posição em dispu$\mathrm{ta}^{17}$. Há três coisas diferentes e interligadas, o conceito de arte, a criação de obras de arte e as obras de arte. Dickie (1984) afirma que sem um conceito de arte, que ele define como pensamentos e conhecimentos sobre arte, não poderíamos criar obras de arte. Mesmo que isso estivesse correto,

\footnotetext{
${ }^{17}$ Dominic Lopes faz uma defesa dessa posição em "Art Without 'Art”"(2007).
} 
não há boas razões para afirmar que a arte é institucional. Além de que, se for possível criar arte sem o conceito de arte, seu argumento não se sustenta. Assim, o que Dickie propõe está comprometido com a tese de que só há arte se há um conceito de arte. No entanto, podemos pensar em casos em que não há o conceito de arte em determinado grupo social, como por exemplo em alguma tribo isolada ou parcialmente isolada e que, mesmo assim, há arte. Assim como é aceitável que nem tudo que é arte foi produzido com a intenção de que fosse arte, ou com pensamentos e conhecimentos sobre arte. Embora Dickie (2004), em um de seus escritos mais recentes, tenha acordo que possa existir arte sem o conceito de arte, todas as suas formulações da teoria institucional vão em direção oposta a essa posição.

Podemos inferir da definição, "[u]ma obra de arte é um artefato de uma espécie criada para ser apresentada a um público do mundo da arte" (DICKIE 1984, p. 157), que a arte rupestre - desenhos e pinturas feitos há milhares de anos em paredes de cavernas, como as de Altamira na Espanha e Lascaux na França -, não é arte. Algo que contraria nossas intuições e o que temos considerado como parte importante da história da arte. Assim, a definição institucional fornece uma boa proposta para incluir ready-mades em sua extensão, mas exclui parte importante da história da arte e, além disso, a arte não ocidental, a arte de rua, entre outros casos.

Robert Stecker (1986) alega que a definição institucional falha em distinguir obras de arte de outros artefatos e assim não apresenta condições suficientes que algo deva satisfazer para ser arte. Isso ocorre, segundo Stecker, porque Dickie (1984) não distingue sistema do mundo da arte de 
qualquer outro sistema de apresentação de artefatos, como por exemplo, o mundo do comércio. Dickie recorre ao termo "arte" para fazer a distinção, o que recai em circularidade e é pouco informativo. Segundo Stecker, Dickie também não mostra que a existência de um enquadramento institucional é uma condição necessária para a arte. Stecker (1986, p. 129-130) alega que nem tudo que é arte é feito para ser apresentado a um público do mundo da arte. A arte rupestre é um exemplo, mas é provável, segundo Stecker, que que isso também ocorra contemporaneamente. Além disso, para Dickie, se Brillo Box é arte, isto é devido a existência de um enquadramento institucional da arte. No entanto, segundo Stecker (1986, p. 130), é difícil ver que disso se segue a conclusão da necessidade de tal enquadramento institucional para todas as obras de arte.

Por fim, não menos importante, uma das principais críticas feitas à teoria institucional por vários filósofos é a da circularidade na definição. Já na primeira versão da definição institucional, Dickie admite que ela é circular, ou seja, que o definiendum (o que se quer definir) aparece no definiens (o que o define). Assim, quer-se definir arte, mas o termo que se quer definir aparece como parte da definição, gerando a circularidade. $\mathrm{Na}$ reelaboração, Dickie dedica uma parte considerável de seus escritos para justificar que sua definição é informativa, portanto, não viciosa apesar de circular. Mesmo usando o termo "arte" no definiens ele alega que explica relações e dá informações para a compreensão do definiendum. Por isso a definição, segundo Dickie, não é 
prejudicada pela circularidade ${ }^{18}$. Mas se ele define a obra de arte como um artefato de uma espécie criada para ser apresentada a um público do mundo da arte, como sabemos o que é o mundo da arte sem antes sabermos o que é a arte ou obra de arte? $\mathrm{O}$ conceito de arte, ou obra de arte, parece ser relevante para a definição de "artista" e pressuposto para definir o "mundo da arte" (e os conceitos relacionados: público e sistema do mundo da arte).

\section{A Última ElaboraÇão De DiCKIE: A ARTE COMO ESPÉCIE CULTURAL}

Em escritos posteriores a The Art Circle (1984), Dickie (2001, 2004) defende que a arte pode ser uma "espécie cultural” (cultural kind). Dickie (2001, p. 2) afirma, "[...] tentei aplicar ao problema da definição de arte uma versão reduzida (scaled-down) da abordagem extensional de Kripke/Putnam que não envolve 'necessidade' e vê a arte como uma coisa cultural e institucional". Dickie distingue a natureza de ouro, uma espécie natural (natural kind), da natureza de "solteiro". Embora o ouro tenha sido por muito tempo definido como uma "substância amarela e maleável", descobriu-se que o ouro possui a propriedade de ser o elemento de número atômico 79. Assim, Dickie concorda com a tese de Kripke (1980) de que o ouro é o "elemento que pos-

\footnotetext{
${ }^{18}$ Dickie (1984, p. 161) chama o "artista”, a "obra de arte", o "mundo da arte" e o "sistema do mundo da arte" de "conceitos inflexionados". Ele usa a expressão "conceitos inflexionados" para designar conceitos que são membros de um conjunto de conceitos que se dobram sobre si mesmos, em que nenhum membro de tal conjunto pode ser compreendido independentemente dos demais.
} 
sui número atômico 79" em todas as situações possíveis em que ouro exista. Dickie (2001, p. 29) considera que não ocorre o mesmo com a espécie cultural solteiro, que não possui uma natureza intrínseca como a do ouro e sim, uma natureza que um indivíduo adquire em um dado contexto cultural. A natureza dos objetos que caem sob a extensão do termo "solteiro" não é descoberta como a dos objetos que caem na extensão de "ouro". Ele afirma que a propriedade de ser solteiro é especificada e inserida em uma prática cultural convencionalmente. Para Dickie, o conceito de "arte" é como o de "solteiro": ambos são espécies culturais ${ }^{19}$.

Dickie, reafirma com essa nova abordagem as cinco definições apresentadas em The Art Circle, que vimos anteriormente na reelaboração da teoria institucional. Ele defende que existe um vínculo íntimo entre a intensão de "solteiro" e a natureza dos membros de sua extensão, ambos são determinados culturalmente. Segundo Dickie (2004, p. 60), participamos da iniciação e manutenção das naturezas culturais, como por exemplo no caso de ser um solteiro. Existe igualmente um vínculo entre o termo cultural "obra de arte" e a sua natureza. Esta pode ser investigada e transformada em uma definição. Ainda não sabemos qual a natureza subjacente da "arte", ela não é tão transparente

\footnotetext{
${ }^{19}$ Dickie $(1997,2000)$ também usa "espécie cultural" e "espécie natural" para classificar teorias da arte, em que a teoria institucional da arte seria um exemplo do primeiro tipo, e a teoria da expressão da emoção seria um exemplo do segundo. Dickie contrapõe-se a distinção feita por Davies (1991) entre definição funcional (functional) e definição procedimental (procedural). Definições funcionalistas, de acordo com Davies, são aquelas que definem a arte de acordo com a função ou funções que elas exercem nas atividades humanas, como por exemplo a função de proporcionar uma experiência estética. Definições procedimentalistas, por outro lado, definem a arte de acordo com certas regras e procedimentos pelos quais ela é criada, como por exemplo a definição institucional de Dickie, cuja a condição de obra de arte é atribuída por meio de um procedimento.
} 
como a de "solteiro", de acordo com Dickie. Mas, caso investigássemos a nossa cultura, ou caso antropólogos culturais o fizessem, Dickie $(2004$, p. 61) imagina que chegaríamos às cinco definições apresentadas por ele ou a algo próximo a elas.

Podemos conceder que a natureza da "arte" assim como a de "solteiro" não é algo descoberto como a natureza de "ouro", mas sim uma natureza "especificada e inserida em uma prática cultural convencionalmente", como propõe Dickie. Porém, isso nos dá razão para retomarmos a crítica de Beardsley, a lembrar, que da instauração de uma prática social por uma convenção não se segue que uma prática social e os objetos que criamos dentro dela sejam institucionais. De modo que ainda nos faltam informações sobre o que faz uma obra de arte ser uma obra arte.

A abordagem de espécies naturais de Kripke/Putnam e sua aplicação à teorização sobre a arte não deixa de ser interessante e merece uma discussão mais aprofundada do que pode ser feita aqui ${ }^{20}$. De qualquer maneira, caracterizar a arte como uma "espécie cultural" não é apresentar a existência de uma instituição como uma propriedade essencial da arte. A versão de Dickie $(2001,2004)$ da abordagem extensional não envolve uma propriedade que obras de arte possuam necessariamente em todas as situações possíveis em que existam. Mesmo que Dickie (2004) defenda que a estrutura apresentada pelas cinco definições na reelabora-

\footnotetext{
${ }^{20}$ James Carney (1975), por exemplo, defende que a "arte" é um designador rígido. Sua abordagem foi criticada por Peter Kivy, Thomas Leddy e por George Dickie. Cf. Dickie (2004). Há um debate em Putnam (1975), Schwartz (1978), Kornblith (1980), entre outros, sobre se a mesma teoria da referência para termos de espécies naturais se aplica a termos de espécies artefatuais ou a outros termos gerais. Cf. Thomasson (2004).
} 
ção da teoria institucional constitui a "essência cultural da instituição dentro da qual a arte tem seu ser". E, que a definição de obra de arte é "a afirmação da essência cultural de uma obra de arte", porque "identifica arte com a propriedade complexa de ser um artefato criado para ser apresentado a um público do mundo da arte" (DICKIE 2004, p. 58). Dickie não consegue mostrar que obras de arte são essencialmente institucionais.

\section{CONCLUSÃO}

A busca por uma função cultural essencial da arte que possa ser expressa em uma definição é um projeto de grande importância. A teoria institucional da arte mostra que é possível apresentar uma definição de arte em termos de condições necessárias e suficientes. Nesse aspecto, reside sua importância. Contudo, segundo Beardsley, a teoria institucional da arte não responde à questão "O que é arte?" de forma tradicional. Uma resposta de certa forma influenciada pelos que negaram a existência de uma essência da arte.

Por mais refinada que a teoria institucional proposta por Dickie seja e tenha ganhado notoriedade no auge dos debates sobre definição de arte, as críticas de Beardsley apontaram problemas centrais na teoria que levaram à sua reelaboração. Como tentei mostrar neste artigo, Dickie respondeu às críticas e reelaborou sua teoria, mas não as respondeu de forma satisfatória. Isso, é claro, não significa que a posição sustentada pelos que negaram a possibilidade de se definir arte esteja correta. Os problemas na teoria institucional da arte, assinalam que o campo para a busca de 
uma definição de arte, não segue apenas controverso, mas, sobretudo, em aberto.

Por fim, pensar a arte como uma espécie cultural, de acordo com a proposta de Dickie, deixa em aberto a existência de uma natureza subjacente da arte, que ainda pode ser investigada. Dickie acha que essa natureza muito provavelmente se aproxime de sua proposta de definição institucional de arte. Contudo, esse campo de estudos ainda pode nos mostrar algo diferente. Espero que este artigo contribua com novas reflexões e as instigue.

Abstract: This paper examines the arguments presented by Monroe Beardsley against the thesis that art is essentially institutional. Beardsley's criticism targets the most refined version of an institutional theory of art, namely George Dickie's theory. He argues that Dickie employs the term "institution" ambiguously, as a token and a type, and that asserting the existence of an institutional context is not the same as claiming that the activities that presuppose this context are institutional. This paper is intended to show that although Dickie restated his theory to reinforce his initial thesis, he cannot satisfactorily respond to so-called "Beardsley-Anscombe Argument". In addition, this papers briefly presents and discusses Dickie's latest approach, in which he argues that art is a cultural kind.

Keywords: Philosophy of art; definition of art; institutional theory of art; cultural kind.

\section{REFERÊNCIAS}

ANSCOMBE, G. Elizabeth. M. On Brute Facts. Analysis, v. 18, n. 3, p. 69-72, janeiro, 1958.

BEARDSLEY, Monroe C. (1976). Is Art Essentially Institutional? In: . The Aesthetic Point of View. Ithaca, NY; London: Cornell University Press, 1992.

CARNEY, James. Defining Art. British Journal of Aesthetics, v. 15, n. 3, p. 191-206, 1975. 
DANTO, Arthur. The Artworld. The Journal of Philosophy, v. 61, n. 19, p. 571-184, outubro, 1964.

Artworks and Real Things. Theoria, n. 39, p.1-17, 1973.

DAVIES, Stephen. Definitions of Art. Ithaca; London: Cornell University Press, 1991.

DICKIE, George. Defining art. American Philosophical Quarterly, v. 6, n. 3, p. 253-256, julho, 1969. Disponível em: http://www.jstor.org/stable/20009315.

What is Art? An Institutional Analysis. In: . Art and the Aesthetic: An Institutional Analysis. Ithaca, NY: Cornell University Press, 1974. Reimpresso In: The Philosophy of the Visual Art. NY: Oxford University Press, 1992, p. 426-427.

- (1984). A Teoria Institucional da Arte. Tradução de alguns capítulos de The Art Circle. In: MOURA, Vítor. (Org). Arte em teoria. Uma antologia de estética. Coordenação e tradução de Vítor Moura. Braga; Ribeirão: Edições Humus, 2009. (Coleção: Antologias).

. Art: Function or Procedure: Nature or Culture. The Journal of Aesthetics and Art Criticism, v. 55. n. 1, p. 1928, 1997.

. The Institutional Theory of Art. In: CARROLL, Noël (org.). Theories of Art Today. Madison: University of Wisconsin, 2000.

. Art and Value. Oxford: Blackwell, 2001.

. Defining Art: Intension and Extension. In: KIVY, 
Peter. (Org). The Blackwell Guide to Aesthetics. Oxford: Blackwell, 2004.

DIFFEY, Terry J. The Republic of Art. British Journal of Aesthetics, p. 145-156, 1969. Disponível em: https://doi.org/10.1093/bjaesthetics/9.2.145

KRIPKE, Saul A. Naming and Necessity. Cambridge: Harvard University Press, 1980.

LOPES, Dominic. Art Without 'Art'. British Journal of Aesthetics, v.47, n. 1, p. 1-15, 2007. D

MANDELBAUM, Maurice. Family Resemblances and Generalization Concerning the Arts. American Philosophical Quarterly, v. 2, n. 3, p. 219-228, julho, 1965.

MOROKAWA, Rosi Leny. Definir ou não definir arte: objeções à tese da impossibilidade da definição de arte e perspectivas teóricas após Morris Weitz. ARS (São Paulo), São Paulo, v. 16, n. 34, p. 93-111, dezembro, 2018.

. Definição de Arte. In: IMAGUIRE, Guido; CID, Rodrigo (Orgs.). Problemas de Metafísica Analítica, Pelotas: NEPFIL Online, 2020. No prelo.

PUTNAM, Hilary. The Meaning of 'Meaning'. In: Mind, Language and Reality, Cambridge: Cambridge University Press, 1975.

STECKER, Robert. The End of an Institutional Definition of Art. The British Journal of Aesthetics, v. 26, n. 2, p. 124-132, fevereiro, 1986.

THOMASSON, Amie. The Ontology of Art. In: KIVY, Peter. (Org). The Blackwell Guide to Aesthetics. Oxford: 
Blackwell, 2004.

WEITZ, Morris. The Role of Theory in Aesthetics. The Journal of Aesthetics and Art Criticism, v. 15, n. 1, p. 2735, setembro, 1956.

WITTGENSTEIN, Ludwig. (1953). Investigações Filosóficas. Tradução José Carlos Bruni. São Paulo: Editora Nova Cultural, 1999 (Coleção: Os Pensadores). 
